\title{
Can the concept of "lean management" be applied to academic recruitment? - a quasi-theoretical discourse
}

\author{
Vic Benuyenah
}

\author{
School of Business, Economics and Informatics, Birkbeck College, \\ University of London, London, UK and Business Division, \\ Dubai Women's College, Dubai, United Arab Emirates
}

\begin{abstract}
Purpose - This paper seeks to emphasise the need to re-evaluate university teacher recruitment processes. The implementation of lean processes helps to improve organisational practices; in the case of university recruitment, however, organisational processes have remained unchanged for decades. Although there is a traditional justification for having academic recruitment as a rigorous and complex process (as a practiced method by which to identify the most suitable applicants), the increase of competition across the sector, and the internet revolution, has rendered these older methods partially ineffective. The author argues that recruitment systems and practices need reviewing to overhaul inefficacious elements.
\end{abstract}

Design/methodology/approach - This is a quasi-literature discourse combined with the author's experience in human resources management teaching and recruitment expertise at the Higher Education level.

Findings - Lean approach if successfully introduced to academic recruitment might reduce the effect of discouraged job seekers paradox and workload on human resources (HR) officers.

Research limitations/implications - The volume of studies reviewed is limited, and therefore, more empirical findings are required in the area of lean recruitment.

Practical implications - HR departments of universities might consider practices that will improve the recruitment process and promote labour force participation.

Originality/value - According to the author's knowledge, lean concept has been applied to HR (recruitment) for the first time in this study.

Keywords University recruitment, Discouraged job seekers, Easy apply options, Lean HRM, Lean recruitment

Paper type Viewpoint

\section{Background and historical context}

Traditionally and much earlier on in work history, application packs were sent back and forth between the employer and the applicant (Pendlebury, 1970). Later, shortly after the internet revolution, most recruitment processes migrated to virtual spaces - with the

(C) Vic Benuyenah. Published in Rajagiri Management Journal. Published by Emerald Publishing Limited. This article is published under the Creative Commons Attribution (CC BY 4.0) licence. Anyone may reproduce, distribute, translate and create derivative works of this article (for both commercial and non-commercial purposes), subject to full attribution to the original publication and authors. The full terms of this licence may be seen at http://creativecommons.org/licences/by/4.0/legalcode

JEL classification - M10, M12

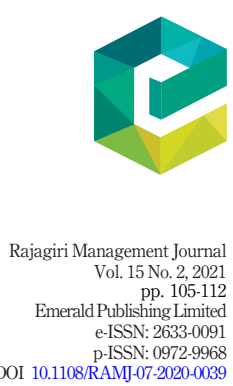


RAMJ

15,2

106

exception of some universities in remote locations, where the internet was not available. In and of itself, this quick adaptation is remarkable; however, most universities failed to introduce the concept of "lean systems" into the recruitment process. Much similar to "lean thinking", the concept of "lean processes" advocates for eliminating waste and for process improvement (Paro and Gerolamo, 2017), a philosophy that has helped Toyota achieve great leaps in its quality system, employee quality and recruitment practices. Why is it that universities cannot improve their current systems by cutting down on labour-intensive processes - for example, by eliminating questions that could be answered elsewhere or those questions that simply do not add extra value - to filter out the weaker applicants? Were the process and the number of questions to be streamlined, university recruitment systems would be in line with the easy apply (EA) option, which is currently used by a number of high-profile recruitment agencies, including www.indeed.com and www.linkedin.com. This assertion is not to elevate EA options (Benuyenah, 2020) as the perfect alternative to complicated university recruitment systems - far from that. The idea is to evaluate the cons of existing practices that potentially discourage applicants from participating in the recruitment process whilst serving as additional work for the already busy human resources (HR) team. In the recent data collected from 13 different countries (Brazil, Canada, Denmark, Finland, Ghana, Malaysia, New Zealand, Sweden, the UAE, the UK, Uganda, the USA and Vietnam), it was discovered that EA options attracted over $83 \%$ of applicant interest compared to traditional generic application process (TGAP; Benuyenah, 2020). Those in favour of TGAP might reason that "if applicants can't be bothered to go through the lengthy process of recruitment, then they are not fit for the organisation in the first place". To me, this is a valid pushback from a hypothetical standpoint; however, the idea is about improvement rather than condemnation. Equally, proponents of TGAP cannot guarantee the correlation between lengthy and complicated (not the same as rigorous) recruitment process and employee commitment and loyalty. Improvement in terms of cutting down on the length of application forms, avoiding duplicated questions (Table 2), cutting down on long waiting period between recruitment and selection phases, reducing long waiting period between the selection phase and offers, etc., are potential benefits for both employees and organisations. Thus, within the context of the two opposing views on EA and TGAP, a critical research question can be posed as: what are the benefits of EA vis-a-vis the weaknesses of TGAP? With this question in mind, we can now turn to the background of lean management as it is framed in the broad literature.

\section{Scope and literature}

\subsection{Scope}

The rest of this paper is characterised by persuasive dialogue, yet some might portray it in some ways as a rhetorical discourse (Fisher, 1985); nonetheless, as this research implies limited replication, the procedure adopted is the quasi-narrative review (Poucher et al., 2019). A narrative review allows for the author's opinion to be used as the interpretative feature of the research (Merriam and Tisdale, 2016) as the researcher attempts to "personalise the research process in a way not easily achieved through quantitative designs, yet demands its own set of procedures and techniques". The rationale is to allow the selected literature sources to consolidate the shared experience of the author who has been part of the higher education hiring process of a number of British universities.

\subsection{Background of lean management}

Lean management, its foundation and promotion have been attributed to Ohno (1988). In operations and manufacturing, the concept has been defined as waste elimination, whereas waste elimination itself is associated with the Toyota Production System (Emiliani, 2006). 
With the solid and incontrovertible quality products from the "Toyota Concept", several organisational systems have borrowed and applied the scheme to improve their processes. In extreme cases, lean systems are seen as identical to just-in-time processes (Taj and Morosan, 2011), whereas others believe that lean six sigma can improve organisational operations including profitability (Randhawa and Ahuja, 2017). As the world is now, more than ever, conscious of ethical and responsible practices (also called corporate social responsibility [CSR]), it is expected that improvements identified in other sectors that make such operations more responsible and "green" be brought into HR services, including recruitment.

\subsection{Lean applications in human resources management}

A number of factors including national culture, organisational climate, context and the individual's disposition towards and interpretation of happiness have been identified as promoting employee happiness (Benuyenah and Pandya, 2020). In contrast, micro-factors such as workload and burnout can contribute immensely to employee unhappiness. In this regard, an unnecessary workload at the HR department because of the lack of lean methods can increase the aggregate level of unhappiness in tertiary institutions. At the moment, both the awareness of lean recruitment and its practice have largely been excluded from the CSR and green human resources management (HRM) discussion (Ajina et al., 2020; $\mathrm{Xu}, 2020$ ). Instead, CSR discussions focus on subjects such as sustainability (Millar and Searcy, 2020), brand value (Ajina et al., 2020) and to a large extent green HRM (Chaudhary, 2018; Shen et al., 2019; Suharti and Sugiarto, 2020). The continuous eschewing of "lean" in CSR and the HR discourse has led to some writers questioning the efficacy of the current recruitment practices in organisations (Cappelli, 2019). As the practice of lean recruitment is underrepresented, so is the specific academic discourse and perhaps the volume of desirable studies that can direct future practice. As we ponder over how to improve the deficiency, it is consequential to start musing over the research agenda for the near future where current recruitment practices will be evaluated in terms of their efficacy. To do this, we first need to formulate a tentative definition for lean recruitment. Lean recruitment involves practices that eschew longwinded processes and requirements that neither add value to the applicants' experience nor the employer's objective. This approach to defining lean recruitment fits in with the broad agenda of the green HRM movement as evident in the work of Chaudhary (2018), Shen et al. (2019) and Suharti and Sugiarto (2020). Therefore, the debate on lean recruitment, particularly within higher education, might encompass ideas on practices that move HR activities away from wasteful, costly and inefficient practices that potentially reduce applicants' interest (also called discouraged job seekers hypothesis). Although discouraged job seekers hypothesis suggests that applicants tend to avoid complicated and lengthy application processes, such lengthy and complicated applications inadvertently also increase the volume of work for the HR department.

Given that the corporate world is naturally complacent and generally adamant to changes, the status quo is not envisaged to change anytime soon. Higher education recruitment will still principally use methods, techniques and practices that are generally tedious (Cappelli, 2019) and counterproductive (Galanaki, 2002; Pollitt, 2005; Yuvaraj, 2016) compared to "EA" options. Despite the fact that university teaching jobs require sound qualification and knowledge as well as skills, a lengthy application process may just be as good as a curriculum vitae (CV) and a cover letter. To reduce waste in the recruitment process would require chopping out parts of the processes that are deemed ineffective or wasteful while at the same time eliminating duplications. 


\begin{tabular}{l} 
RAMJ \\
15,2 \\
$\mathbf{1 0 8}$ \\
\hline
\end{tabular}

\section{Discussion and practical rationale}

3.1 Do application forms duplicate information from $\mathrm{CV}$ s/resumes?

As hinted earlier, more research aimed at investigating lean recruitment is required to help modernise HR practice, promote applicant engagement (Mansor et al., 2014; Kumar and Pansari, 2015) and support CSR intentions. One way to start thinking about improvements is to consider the benefits of the ideas on the principles of lean management (Table 1), which have been widely used in manufacturing (Emiliani, 2006; Hernandez-Matias et al., 2019) and other business processes (Paro and Gerolamo, 2017; Randhawa and Ahuja, 2017). If implemented, lean recruitment might provide values shown in Table 1.

Whereas the expansive discussion of the lean principles is not within the objective of this paper, the application of individual items from Table 1, such as "value stream", "flow" and "perfection" in particular, might be useful to higher education recruitment whereas at the same time, form the basis for deeper academic enquiry. The principle of perfection would suggest the realisation of the ideal situation - in this case, what methods are more prone to satisfying the needs of employers.

To be fair, HR recruiters are professional and perfectionists, and to maintain the level of perfection applied in their roles, some might want to continuously improve what they currently do including university recruitment. It is doubtful that there is a single professor or teacher in the field who does not have a resume or $\mathrm{CV}$, yet often, the nature of application form questions duplicates the information already on $\mathrm{CV}$ (Table 2) and resumes. In the scenario below, for example, much of the information solicited on an application form could be obtained elsewhere, if the "lean" concept were to be adopted. One major critique at this point is that the employer often asks for a $\mathrm{CV}$ and cover letter or personal statement while simultaneously asking for an application form to be completed in full. University recruitment teams can therefore reflect on the sample framework of duplicated information during the application process in Table 2 .

Table $\mathbf{1 .}$
Lean philosophy in higher education recruitment
Lean principle Philosophical intention in recruitment

Specify value

Create value for the applicant (time, logistics and efforts)

Value stream

Reduce complexity, redundancy and multiple requests

Flow

Pull

Perfection
Create value flow, eliminate long waiting times
Request only what is feasible, consider the impact on the applicant

Realisation of the ideal situation by consistent and holistic identification and elimination of non-value-added activities or wastes associated with a business function or service.

For example, EA vs traditional approaches

\begin{tabular}{lll}
\hline Recruitment question/information & Duplicated in & Can be obtained after shortlisting \\
\hline Address and telephone number & CV/resume & \\
Biodata & CV/resume & \\
Personal statement & Cover letter \\
Teaching philosophy & Potentially in CV objective \\
Current employer & CV/resume \\
References & Usually in CV/resume \\
List of publications & Usually in CV/resume \\
Years of experience & CV/resume/cover letter \\
Note: Not all recruiters will ask for both or all of the above at the same time
\end{tabular}

Table 2.

Duplicated information across CVs/resumes and application forms
Note: Not all recruiters will ask for both or all of the above at the same time 

inefficiencies inherent in the use of complicated and lengthy forms (Cappelli, 2019), universities continue to use these current approaches for the following benefits:

- The TGAP allows for detailed information to be collected and stored, making future planning easier for the HR department. As most would agree, however, rarely do universities refer to this database when new recruits are sought - at least, not in my own anecdotal experience. In some countries, such as the UK, the USA and Canada, government institutions are required by law to advertise new positions, which means that old candidate data are potentially rendered obsolete anyway.

- Theoretically, we can argue that a standard university application form helps to screen the weaker applicants out of the recruitment process, but there is a counterargument to this; just as IQ tests and other forms of competitive tests, applicants tend to master the responses required for most of the recruitment questions after a few trials. Given the justification for a more complex process, there is a further risk that the form is outsourced to an expert by an applicant, who might fill out the form for a candidate, which raises the question of reliability.

\section{Practical recommendations}

As a way to improving current recruitment practices, particularly in the higher education sector, the following considerations are made:

- Rather than ignoring the wave of changes happening to recruitment processes used by online agencies, universities could review their current forms to locate areas that could be trimmed down. Questions that could be answered elsewhere can be eschewed - unless there is a rationale in place around question repetition, where it is used to triangulate applicants' responses and establish their level of integrity, for example. There is little benefit to this in practice as it puts an extra responsibility on the applicant and the HR officer dealing with the pool of applications.

- Although advertising for positions and collecting data on potential employees is desirable in terms of future workforce planning, this practice is slightly unethical, as it tends to mislead potential candidates. To mislead applicants is quite similar to breach of employee happiness (Benuyenah and Pandya, 2020) no matter how insignificant that might be. Perhaps universities should request only CVs when they are building a pool of potential candidates; it is certainly disreputable to ask applicants to submit a long application form with little or no chance of actual employment.

- If at all possible, the gap between the recruitment and selection phases should be narrowed so as to give credibility to the organisations' hiring process (Cappelli, 2019). Candidates must frequently wait for months only to be told that their application was unsuccessful. Even if an applicant is successful, such long delays can render the recruitment process ineffective.

- In most cases, a simple $\mathrm{CV} /$ resume can do the same job as a 12-page application form.

- If the intention is to collect biodata and other essential candidate information, this could be done at a later stage, once the candidate has been shortlisted: this will be in line with "flow" and "value steam" (Emiliani, 2006; Randhawa and Ahuja, 2017; 
RAMJ

15,2

Ajina et al., 2020). In so doing, the candidate is less likely to be given false hope and more likely to have a favourable view of the effort-to-outcome ratio in the recruitment process.

- Speculative adverts and recruitment campaigns are unethical, as candidates have no way of knowing that a job is not immediately available. To reduce anxiety and waiting times (Emiliani, 2006; Hussain and Malik, 2016; Randhawa and Ahuja, 2017), an honest workforce planning should be carried out.

- If possible, EA options (in which a CV/resume and cover letter suffice in most cases) should be used as the first stage of the recruitment process. This may vary depending on the recruitment intentions and organisational type; however, applying this method can fulfil the "pull" and "perfection" principles of lean (Randhawa and Ahuja, 2017; Hernandez-Matias et al., 2019).

\section{Research implications/agenda}

As can be seen from Sections 2 and 3, several gaps exist within the HR and organisational literature. To advance the literature, the following recommendations are made.

\subsection{Lean recruitment and higher education}

To extend the principles of lean recruitment to higher education, a future research work can explore how the lean recruitment is contextualised within the green HRM domain (Chaudhary, 2018; Shen et al., 2019; Suharti and Sugiarto, 2020) and broadly within the field of CSR (Khan et al., 2019; Damoori et al., 2020). Some may assess whether lean recruitment actually fits in with the HRM green domain, and if so, in what specific ways; others might take a different angle by proposing that lean recruitment is incompatible with the two fields.

\subsection{Validation of lean systems}

As the benefits of lean recruitment are not currently validated across all recruitment agencies and professional networking sites, an opportunity exists for researchers to extend our understanding of LinkedIn profiles and job search (Zide et al., 2014), personality perception based on e-recruitment (van de Ven et al., 2017) and how other social networking tools (Nikolaou, 2014) support the recruitment function.

\subsection{Lean systems and engagement, commitment and loyalty}

The link between lean recruitment practices and employee commitment or engagement (Attridge, 2009) remains a fuzzy research area. Perhaps a future research can investigate the link between the variables in the lean management concept and their influence on later employee commitment (Elele and Fields, 2010), engagement (Kumar and Pansari, 2015) and loyalty (Guillon and Cezanne, 2014). The question can be, "to what extent does TGAP ensure that only the right caliber of employees likely to commit to the organisation are recruited?"

\subsection{Industry-wide extrapolation of lean concept}

Rather than pause the research enquiry at higher education practices, some researchers might explore the benefits of lean systems in other educational settings including further educational and non-tertiary institutions. 


\section{Conclusion}

Despite its application to operations and management, the concept of lean is not currently applied to higher education recruitment practices. This leaves a chasm in the organisational literature and leads to potentially suboptimal outcomes whereby applicants are discouraged and employers are overburdened with lengthy processes. Although this subject remains highly contestable, this opinion piece sets the foundation for imminent research work on lean recruitment.

\section{References}

Ajina, A.S., Roy, S., Nguyen, B., Japutra, A. and Al-Hajla, A.H. (2020), "Enhancing brand value using corporate social responsibility initiatives: evidence from financial services brands in Saudi Arabia”, Qualitative Market Research: An International Journal, Vol. 23 No. 4, 71672058,

Attridge, M. (2009), "Measuring and managing employee work engagement: a review of the research and business literature", Journal of Workplace Behavioral Health, Vol. 24 No. 4, pp. 383-398.

Benuyenah, V. (2020), "Discouraged job seekers' hypothesis: applicant attraction to 'easy-apply' options and salary details in online labour market”, [Manuscript submitted], Dubai Women's College, UAE.

Benuyenah, V. and Pandya, B. (2020), "Meaning of 'employee happiness' within the context of complex organisations: an explanatory review on the UAE labour force", Rajagiri Management Journal, Vol. 14 No. 2.

Cappelli, P. (2019), "Your approach to hiring is all wrong”, Harvard Business Review, 2019 (May-June), pp. 3-10.

Chaudhary, R. (2018), "Can green human resource management attract young talent? An empirical analysis", Evidence-Based HRM, Vol. 6 No. 3, pp. 305-319.

Damoori, D., Alhosseini Almodarresi, S.M. and Jafari, S. (2020), "Conceptualization of a multi-level social responsibility model in the public sector: a mixed-methods approach", Journal of Modelling in Management, Vol. 15 No. 3, pp. 1746-5664.

Elele, J. and Fields, D. (2010), "Participative decision making and organisational commitment", Cross Cultural Management: An International Journal, Vol. 17 No. 4, pp. 368-392.

Emiliani, M.L. (2006), "Origins of lean management in America: the role of Connecticut businesses", Journal of Management History, Vol. 12 No. 2, pp. 167-184.

Fisher, W.R. (1985), “The narrative paradigm: an elaboration”, Communication Monographs, Vol. 52 No. 4, pp. 347-367.

Galanaki, E. (2002), "The decision to recruit online: a descriptive study", Career Development International, Vol. 7 No. 4, pp. 243-251.

Guillon, O. and Cezanne, C. (2014), "Employee loyalty and organisational performance: a critical survey", Journal of Organizational Change Management, Vol. 27 No. 5, pp. 839-850.

Hernandez-Matias, J.C., Ocampo, J.R., Hidalgo, A. and Vizan, A. (2019), "Lean manufacturing and operational performance: interrelationships between human-related lean practices", Journal of Manufacturing Technology Management, Vol. 31 No. 2, pp. 217-235.

Hussain, M. and Malik, M. (2016), "Prioritising lean management practices in public and private hospitals", Journal of Health Organization and Management, Vol. 30 No. 3, pp. 457-474.

Khan, N.U. Saufi, R.A. and Rasli, A.M. (2019), "Green human resource management practices among ISO14001-certified Malaysian manufacturing firms", Green Behavior and Corporate Social Responsibility in Asia, (May), pp. 73-79. doi: 10.1108/978-1-78756-683-520191009.

Kumar, V. and Pansari, A. (2015), "Measuring the benefits of employee engagement", MIT Sloan Management Review, Vol. 56 No. 4, pp. 67-72.doi, doi: 10.1111/j.1754-9434.2007.0002.x. 
RAMJ

15,2

Mansor, M., Halim, N.H., Mohd Yusof, B.N. and Abu, N.H. (2014), "Factors influencing decision on job application: a study of graduate's business school perspective", Australian Journal of Basic and Applied Sciences, Vol. 8 No. 1, pp. 499-507.

Merriam, S. and Tisdale, E.J. (2016), Qualitative Research: A Guide to Design and Implementation, (4th ed.), John Wiley and Sons, San Francisco.

Millar, E. and Searcy, C. (2020), "The presence of citizen science in sustainability reporting", Sustainability Accounting, Management and Policy Journal, Vol. 11 No. 1, pp. 31-64.

Nikolaou, I. (2014), "Social networking web sites in job search and employee recruitment", International Journal of Selection and Assessment, Vol. 22 No. 2, pp. 179-189.

Ohno, T. (1988), The Toyota Production System: Beyond Large-Scale Production, Productivity Press, Portland, OR.

Paro, P.E.P. and Gerolamo, M.C. (2017), "Organisational culture for lean programs", Journal of Organizational Change Management, Vol. 30 No. 4, pp. 584-598.

Pendlebury, C. (1970), "Application form design”, Industrial and Commercial Training, Vol. 2 No. 11, pp. 527-529.

Pollitt, D. (2005), "E-recruitment gets the Nike tick of approval: system frees HR staff to perform more consultancy", Human Resource Management International Digest, Vol. 13 No. 2, pp. 33-35. doi: 10.1108/09670730510586995.

Poucher, Z.A., Tamminen, K.A., Caron, J.G. and Sweet, S.N. (2019), "Thinking through and designing qualitative research studies: a focused mapping review of 30 years of qualitative research in sport psychology", International Review of Sport and Exercise Psychology, Vol. 13 No. 1, p. 9858.

Randhawa, J.S. and Ahuja, I.S. (2017), "5S - a quality improvement tool for sustainable performance: literature review and directions", International Journal of Quality and Reliability Management, Vol. 34 No. 3, pp. 334-361.

Shen, J., Dumont, J. and Deng, X. (2019), “Green human resource management in Chinese enterprises", Green Human Resource Management in Chinese Enterprises, doi: 10.4324/9780429286971.

Suharti, L. and Sugiarto, A. (2020), "A qualitative study of green HRM practices and their benefits in the organisation: an Indonesian”, Business: Theory and Practice, Vol. 21 No. 1, pp. 200-211.

Taj, S. and Morosan, C. (2011), "The impact of lean operations on the Chinese manufacturing performance", Journal of Manufacturing Technology Management, Vol. 22 No. 2, pp. 223-240.

van de Ven, N., Bogaert, A., Serlie, A., Brandt, M.J. and Denissen, J.J. (2017), "Personality perception based on LinkedIn profiles", Journal of Managerial Psychology, Vol. 32 No. 6, pp. 418-429.

$\mathrm{Xu}, \mathrm{H}$. (2020), "Corporate social responsibility, product innovation, and product line”, Nankai Business Review International, Vol. 11 No. 2.

Yuvaraj, M. (2016), "Adoption of technology in recruitment of library professionals and faculty members: case study of social media in India”, The Bottom Line, Vol. 29 No. 4, pp. 241-250.

Zide, J., Elman, B. and Shahani-Denning, C. (2014), "LinkedIn and recruitment: how profiles differ across occupations”, Employee Relations, Vol. 36 No. 5, pp. 583-604.

Corresponding author

Vic Benuyenah can be contacted at: vbenuy01@gmail.com

For instructions on how to order reprints of this article, please visit our website:

www.emeraldgrouppublishing.com/licensing/reprints.htm

Or contact us for further details: permissions@emeraldinsight.com 